\title{
Experiencing Your Education: What Engineering Education Can Learn from Dialogue
}

\author{
Janna Rosales, $\mathrm{PhD}$ \\ Research Associate \\ Memorial University of Newfoundland \\ jrosales@mun.ca
}

\author{
Gloria Montano \\ Manager, Academic Programs \\ Memorial University of Newfoundland \\ gloria.montano@mun.ca
}

\begin{abstract}
What do engineers need to know beyond the textbook? Success as an engineer today also depends on the ability to hone skills such as team work, social intelligence and interdisciplinary collaboration, qualities that extend far beyond engineering itself. Dialogue education is one effective method being used in higher education to enhance student success, and it offers intriguing possibilities when paired with the curriculum for professional degrees. When students participate in dialogue education they not only sharpen professional communications skills, but also cultivate a richer understanding of the diverse perspectives which they encounter as they learn to engage constructively with the world around them.

What can engineering education gain from dialogue education? In March 2011, the MetaKettle Project (Faculty of Engineering and Applied Science, Memorial University of Newfoundland), sponsored the "Dialogue Lab", a participatory workshop for graduate and undergraduate engineering students. The purpose of this workshop was to explore the ways that dialogue can be used as a practical and effective tool within the engineering profession in order to construct positive social, political, economic, civic and personal outcomes. This paper will report and reflect upon the results of the Dialogue Lab and examine what role dialogue can play in engineering education.
\end{abstract}

\section{Introduction}

How adequate are standard engineering education curricula in meeting the needs and problems of a future defined by rapid change, increasing complexity, and global impacts? Engineering education researchers and practitioners argue that engineering programs that educate students primarily to be specialized, technical problem solvers are no longer adequate to meet the challenges at hand [1] [2] [3] [4]
[5] [6] [7] [8]. The reality of current engineering practice requires engineers to be problem-definers as well as problem-solvers [9] and thus to understand the social, cultural, economic, environmental, and ethical dimensions of the issues and designs they seek to address. Simply put, engineers need additional skills in order to engage effectively in professional practice. Success as an engineer today requires team work, social intelligence and interdisciplinary collaboration that extends well beyond engineering itself.

Engineering program accreditation boards recognize and are responding to this changing landscape, and are adopting outcomes-based criteria that describe the desired attributes of an engineering graduate [10] [11]. The question with which many institutions now grapple is how to design and deliver curricula that will help students achieve those outcomes. The authors of this paper are also wrestling with this question, but beyond this we contend, in concert with a growing number of others with an interest in engineering education [2] [3] [4] [9], that there is a pressing need-and even obligation-to support educational experiences that do not simply allow students to pass exams and receive certification but which intentionally and systemically prepare and empower graduates to become responsible professionals and engaged citizens who seek to contribute meaningfully to their communities.

This paper will describe and reflect upon a recent initiative undertaken by the MetaKettle Project in the Faculty of Engineering and Applied Science at Memorial University of Newfoundland. Founded in 2010 as a legacy pedagogy project of the 2004-2009 NSERC/Petro-Canada Chair for Women in Science and Engineering (Atlantic Region), the MetaKettle Project aims to increase the diversity of students studying science and engineering, while enhancing the long-term sustainability of graduates over their careers and lives. The MetaKettle Project seeks to do this through initiatives that focus not only on professional skills, e.g., effective communication and 
interdisciplinary collaboration, but more particularly on creating "catalytic experiences" which engage the learner as a whole person. A catalytic experience inspires or motivates students to relate to their knowledge in a personally meaningful way, often by tapping into the individual's unrealized potential through relating significantly to their lived experience.

As part of its investigation into integrative engineering education and catalytic learning opportunities, the MetaKettle Project sponsored the "Dialogue Lab," a participatory workshop for graduate and undergraduate engineering students to explore the role that dialogue might play in engineering education. The Dialogue Lab is inspired by the philosophy and practices that inform dialogue education and draws upon insights shared from the authors' contact with faculty and students in the Undergraduate Semester in Dialogue at Simon Fraser University (SFU) in Vancouver, BC, a highly successful collaborative and interdisciplinary program which focuses on experiential education and civic engagement.

The principles and methods which undergird dialogue education directly relate to a significant number of outcomes and attributes identified by the Canadian Engineering Accreditation Board which, for the authors, was an important reason to organize the Dialogue Lab. We will outline in our discussion section below how dialogue corresponds to those key outcomes. However, beyond simply meeting new accreditation criteria, dialogue education offers students catalytic experiences that have deeply rooted relevance in their own lives, experiences that allow them to think in more creative and more expansive ways. This is even more reason to pay attention to the ways that dialogue education can enhance student success in engineering. When students participate in dialogue education they not only cultivate professional communications skills, but also gain a deeper understanding of a diversity of perspectives, which in turn helps them to engage constructively with the world around them.

\section{Dialogue education in action}

A brief summary of how the Undergraduate Semester in Dialogue at SFU works will provide some context and rationale for the purpose of piloting an engineering-focused Dialogue Lab at Memorial University. Associated with the Morris J. Wosk Centre for Dialogue at the Harbour Centre campus of SFU in downtown Vancouver, the Semester in Dialogue brings together 20 upper year undergraduate students each term from a variety of disciplines (the program is open to all disciplines at SFU) for a fulltime, immersive, theme-based learning experience which challenges participants to engage with issues of public import and personal relevance. What informs the basis of those learning experiences is dialogue. More than just discussion-based learning, dialogue refers to a deeper process of actively listening to and reflecting upon a wide variety of perspectives in order to clarify issues, gain insight, and promote positive action. Assignments and activities are crafted as experiential and catalytic learning opportunities, from writing op-ed pieces to facilitating roundtable discussions with leaders in industry, government and the arts, to hosting public policy forums and events. In short, no project is assigned simply for grades or to appease the instructor; all of them have the potential to generate impact on the community. Now in its ninth year, the Semester in Dialogue has become a "signature program" at Simon Fraser University that allows students to explore who they are and who they want to be in relation to the wider world, sometimes in deeply transformative ways.

SFU's Undergraduate Semester in Dialogue is one example of a growing number of dialogue-based programs, courses, and even certificates in higher education. Dialogue can be understood as a "conversation with a center, not sides" where people "think together in a relationship" and no longer take their own position to be final [12]. The collaborative, rather than competitive, nature of dialogue distinguishes it from other types of interaction and is premised on the notion that no one person has the answer or the expertise but that everyone possesses part of the wisdom. Based upon this premise, dialogue uses focused conversation to do collective exploration, and participants must be willing to set aside their ingrained convictions in order to examine issues from a variety of perspectives in an open and nonjudgmental manner [13]. Unlike encounters through debate or even discussion, the purpose of dialogue is not to fight for specific agendas or advocate for certain outcomes but rather to open up possibilities to see things in new ways. Although there is a constructive place in education and public discourse for more adversarial encounters, this is not the purpose of dialogue. The intent of dialogue is to meet needs that are greater than simply resolving problems or reaching consensus; according to William Isaacs, founder of the Dialogue Project at MIT [12], "[i]t is a way of taking the energy of our differences and channeling it toward something that has never been created before. It lifts us out of polarization and into a greater common sense, and is thereby a means for accessing the intelligence and coordinated power of groups of people”. The dialogue model is based on a belief that the ability to think together yields valuable and profound insights that would not 
otherwise be tapped into were people to focus primarily on defending their views or winning an argument.

The dialogue approach has proven immensely effective in a variety of contexts, from local civic politics to corporate reorganization, from restorative justice to international peace talks [14] [15]. Given the model's success, what might it have to offer engineering education and how might it be adapted to engineering curricula? The Dialogue Lab at Memorial University seeks to address that question.

\subsection{The Dialogue Lab at Memorial University of Newfoundland}

The Dialogue Lab brought together sixteen student participants and nine faculty observers for a two hour workshop facilitated by Dr. Mark Winston, a worldrenowned scientific researcher who developed a passion for dialogue education and subsequently founded and directs the Undergraduate Semester in Dialogue at Simon Fraser University. The session was part of a multi-day series of events organized by the MetaKettle Project at Memorial University, which involved stakeholder consultations, a faculty workshop, a public lecture, and meetings with community groups regarding dialogue, experiential education, and community engagement. Time and resource constraints limited us to providing Dialogue Lab participants only a general introduction to dialogue education but it was important to the MetaKettle Project's science and engineering mandate to offer a workshop in dialogue specifically for those with an engineering interest, as a complement to the week's other activities.

The participants included engineering students from both the graduate and undergraduate levels, as well as three Master's students from Memorial's Graduate Program in Humanities, two of whom had engineering or computer science backgrounds. The majority of participants were graduate students from the Faculty of Engineering.

Student participants self-selected to voluntarily attend the session, which was framed as an invitation to "explore how dialogue can be a practical and effective tool to construct positive social, political, economic, civic and personal outcomes." The session intended to yield tangible techniques and ideas for how to incorporate the skills of dialogue into professional practice and consisted of thinking exercises, guided questioning, reflective writing, narrative, and group discussion.

Although we have indicated ways that dialogue is distinct from other modes of engagement, a story from the Dialogue Lab will further illustrate the differences.
Participants were posed the following scenario: Imagine you are meeting with a senior executive of a major oil-producing corporation invested in the Alberta bitumen reserves. The executive has just made a statement about the need to develop oil sands resources on a wide-scale and at an accelerated pace in order to keep the Canadian economy growing. How would you respond to this statement? What is the first thing you would want to know?

The students responded by saying they would ask for more information about the proposed developments in term of cost, rate of extraction, size of reserves, projected risks involved, and other facts associated with technical considerations.

The facilitator noted the difference between the students' responses and those he typically gets when he poses the scenario to an interdisciplinary group: while the engineering students' inquiries into the project's technical specifications were valid questions to ask, other groups usually take a more ideological stance on the developments, arguing over whether development is a good or bad thing. But beyond the students' rather technical concerns or the hot-button reactions of various potential community stakeholders, the facilitator explained what a dialogic approach to this scenario might be like; he asked the students to imagine how the meeting would be conducted if this were the first response to the oil executive's statement: Tell us more about why you are working in this industry. This approach appeared to take the students by surprise. He explained that what might appear as a superfluous request in a debate or confrontational forum is actually crucial to establishing an environment conducive to dialogue and moreover to promoting a deeper understanding of the issues at stake. Rather than ignoring that dialogic line of inquiry, assuming it was irrelevant to the focus of the meeting, or jumping into the exchange ready to defend their agendas, participants would experience a distinctly different tone in the subsequent conversation, just by committing some time to find out the professional and personal reasons why the oil executive and the other participants are interested in the future of bitumen development. Asking such context-broadening questions opens up space for candor, breaks down adversarial barriers by adding a more human dimension to the situation, and offers greater possibilities for coming to some common understandings.

Dialogue takes a mindful and intentional approach to framing an issue and setting the agenda because it focuses on creating a welcoming and productive environment in which to think together. Many examples of this intentional and collaborative thinking approach already exist in corporate and consulting 
culture, such as through the Thinking Environment model [16], and at the crossroads of technology, design, and academia as at the Anita Borg Institute in Palo Alto, CA [17].

The Dialogue Lab highlighted the need for such intentionality on the behalf of engineers, who are often involved in projects and consultations that broach contentious issues. It is vitally important to establish a respectful and constructive tone to any meeting, but beyond cultivating civility, a commitment to the dialogue process involves more of a personal investment to suspend one's own deeply-rooted views and to really hear where another party is coming from. To do so requires presence, sincerity and a nonjudgmental attitude.

The Dialogue Lab explored these facets through written work and discussion as a brief demonstration of how to cultivate individual qualities that would contribute to an effective dialogue process. The Dialogue Lab provided an overview of what dialogue is, how it works, and why it is relevant in meetings and consultations, and has opened a door to think about what engineering education has to gain from a dialogic approach.

\section{Discussion}

\subsection{How dialogue meets CEAB graduate attributes}

The principles and practices of dialogue education may be uncommon in many traditional engineering programs, but they are far from incompatible, and in fact offer rich and intriguing possibilities when paired with the curriculum for professional degrees. For example, of the twelve graduate attributes identified in the 2010 CEAB Accreditation Criteria and Procedures Report [10], we have noted seven areas which have obvious relevance to skills commonly developed in the general context of dialogue education. These are: individual and team work, communication skills, professionalism, impact of engineering on society and the environment, ethics and equity, economics and project management, and life-long learning. The other five areas (knowledge base for engineering, problem analysis, investigation, design, use of engineering tools) arguably could be adapted to a dialogue setting that focuses specifically on engineering, especially if offered through a cornerstone or capstone engineering design course.

A few words to elaborate on attributes 3.1.6 to 3.1.12 of the Canadian Engineering Accreditation Board criteria will help clarify the potential contribution that dialogue models can make to engineering education.
3.1.6: Individual and team work: An ability to work effectively as a member and leader in teams, preferably in a multi-disciplinary setting.

Dialogue works best when conducted with participants from a variety of backgrounds and disciplines, and unlike the traditional lecture-based or "sage on the stage" format, there is no "expert" in a dialogue situation. Everyone brings valuable understanding to the table and everyone has something to contribute. This quality of dialogue makes participation in it a truly collaborative effort. Moreover, participants in dialogue education have extensive opportunities to develop facilitation and time-management skills.

3.1.7: Communication skills: An ability to communicate complex engineering concepts within the profession and with society at large. Such ability includes reading, writing, speaking and listening, and the ability to comprehend and write effective reports and design documentation, and to give and effectively respond to clear instructions.

Dialogue's stock and trade is in effective communication; participants in dialogue education focus on honing written and oral expression that exhibits clarity, focus, brevity, and impact.

3.1.8: Professionalism: An understanding of the roles and responsibilities of the professional engineer in society, especially the primary role of protection of the public and the public interest.

In a dialogue setting, students get to test the professional identities they are forming through their education. They are able to question usually-tacit assumptions about their roles and responsibilities as professionals because the purpose of dialogue is to open a space for critical thought that clarifies and reevaluates the expectations of all participants. Having the time and opportunity to reflect on one's professional identity allows for a better integration with one's more personal sense of self and contributes to a more meaningful sense of service to one's community.

3.1.9: Impact of engineering on society and the environment: An ability to analyze social and environmental aspects of engineering activities. Such ability includes an understanding of the interactions that engineering has with the economic, social, health, safety, legal, and cultural aspects of society, the uncertainties in the prediction of such interactions; and the concepts of sustainable design and development and environmental stewardship.

Encounters through dialogue with stakeholders from diverse backgrounds highlight the multi-faceted nature of issues that involve engineers. When one adopts the stance that all participants possess valuable pieces of the puzzle and that other people's thinking 
can improve one's own, then new options appear and more sustainable and meaningful solutions can be crafted.

3.1.10: Ethics and equity: An ability to apply professional ethics, accountability, and equity.

Rather than forcing an issue or jockeying for a winning position, dialogue explores areas of common ground. Because participants are able to voice their interests and concerns more openly and honestly, those issues can be addressed in a more comprehensive way. Professionals learn to recognize that ethics is not just about complying with regulations, but rather actively seeking to do good.

3.1.11: Economics and project management: An ability to appropriately incorporate economics and business practices including project, risk, and change management into the practice of engineering and to understand their limitations.

Dialogue has lately gained footing as a viable tool in corporate practice [14] [15] as businesses look for more sustainable ways of making decisions and remaining adaptable and open to change both within their company affairs and in their international business networks. Also, by opening the conversation to a wider variety of interests, dialogue also helps show the limitations of making decisions based on economic factors alone.

3.1.12: Life-long learning: An ability to identify and to address their own educational needs in a changing world in ways sufficient to maintain their competence and to allow them to contribute to the advancement of knowledge.

Effective dialogue requires continual self-reflection on the part of participants, the ability to recognize one's strengths and shortcomings, and the ability to value the strength in others' positions. Through continuous feedback and opportunities to practice required skills (such as written and oral communication) dialogue participants come to engage in realistic self-appraisal and more thoughtful appraisal of the work of others.

\subsection{Future directions for dialogue in engineering}

As we stated in the beginning of this paper, leaders in the engineering profession and in the field of engineering education contend that additional skills are needed to meet the challenges of the $21^{\text {st }}$ Century in a more holistic way: "In this evolving world, a new kind of engineer is needed, one who can think broadly across disciplines and consider the human dimensions that are at the heart of every design challenge. In the new order, narrow engineering thinking will not be enough" [9]. Although this version of the Dialogue Lab lasted only two hours, it represents the potential for a much more involved and systemic contribution to engineering curricula. This workshop modeled in a compressed way what the first week of an introduction to dialogue education would entail were the Dialogue Lab to be a scaled up to a full course, or even to a fullsemester, immersive experience as inspired by SFU's Undergraduate Semester in Dialogue.

It must be noted however, that dialogue is a tool that fits some purposes better than others. It is not meant to replace the traditional lecture format or to usurp pedagogical methods suited to convey large volumes of information. Although it is designed to be a flexible, adaptable process with relevance in many contexts, it will not be appropriate for all situations at all times. It can work well in one-off situations involving up to forty people, but it works best with small groups (up to twenty) which have built up an ongoing relationship centred around a common theme or interest.

That being said, the benefit of dialogue is not limited to a full-blown immersive dialogue experience; elements of dialogue can be incorporated into existing courses or existing courses can be reorganized around the foundations of dialogue. For example, dialogue could be effectively integrated into courses particularly dedicated to the Engineering Workplace, the Engineering Profession, Engineering Ethics, Applied Environmental Engineering, Assessment of Technology, Sustainability, Project Planning, Safety and Risk Assessment, Environmental Assessment, and Labour Relations. Dialogue would be especially useful if introduced into a first-year design course and then revisited in senior design courses. Using dialogue in cornerstone and capstone projects would reinforce the idea that dialogue is not just a process but an ethos intended to cultivate more sustainable, more resilient, and more effective approaches towards defining and solving multi-faceted problems.

\section{Conclusion}

We believe the value of the Dialogue Lab is that it posed questions that many students, and engineering students in particular, may not have considered previously, and it provided an entry point into a new way of thinking about the engineering enterprise. The session challenged the expectations and pushed the comfort zones of many participants, but others expressed that it was a welcome change from what they typically experience in their engineering education, having little time or opportunity to reflect on what they are doing, why they were doing it, or to put it in a context that paid more than a passing nod to 
the wider social, ethical, environmental, and economic implications of the engineering enterprise.

Engineers are integral to the design and production of structures and processes that contribute in complex ways to societal development. Because of the profession's significant impact upon human interaction in direct and indirect ways, leaders in engineering education and industry are taking stock of the changes needed in $21^{\text {st }}$ century engineering curriculum, and have committed themselves to transform engineering education and practice in order to foster greater collaboration, a culture of sustainability, and the best quality of life possible for Canadians [18]. Although skeptics worry about changes that might water down the curriculum, advocates of holistic pedagogy argue that such approaches can fire things up, that a broad-based engineering education is both personally empowering for students and globally competitive for the profession [19].

The practice of dialogue education in an engineering context offers potential for a more integrative approach to problem-solving, which not only provides engineering students more relevant opportunities to effectively build professional skills demanded by industry, but also creates more personally meaningful education experiences.

\section{References}

[1] D. Douglas and G. Papadopoulos with J. Boutelle, Citizen Engineer: A Handbook for Socially Responsible Engineering, Prentice Hall, Upper Saddle River, NJ, 2010.

[2] R..M. Felder, “On Creating Creative Engineers", Engineering Education 77 (4), 1987, pp. 222-227.

[3] P. D. Galloway, "Engineering Education Reform”, Civil Engineering, November 2007, p.46-51.

[4] D.E. Goldberg, “The Missing Basics and Other Philosophical Reflections for the Transformation of Engineering Education”, 2009. Available from http://philsci-archive.pitt.edu/archive/00004551/01/deggrasso-2009-the-missing-basics.pdf.

[5] National Academy of Engineering, The Engineer of 2020: Visions of Engineering in the New Century, Report of a Committee Part 1, National Academies Press, Washington, DC, 2004.

[6] National Academy of Engineering, Educating the Engineer of 2020: Adapting Engineering Education to the New Century, National Academies Press, Washington, DC, 2005.
[7] D.W. Reeve, “There is an Urgent Need for Engineering Leadership Education,” Engineering Leadership Review, May 2010, pp.1-6.

[8] A. Rugarcia, R.M. Felder, D.R. Woods, and J.E. Stice, "The Future of Engineering Education", Chemical Engineering Education 34 (1), 2000, pp.16-25.

[9] D. Grasso and D. Martinelli, "Holistic Engineering”, The Chronicle Review 53 (28), March 16, 2007, p. B8.

[10] Canadian Engineering Accreditation Board (CEAB), Accreditation criteria and procedures, Canadian Council of Professional Engineers, 2009. Available from http://www.engineerscanada.ca/e/files/Accreditation_Criteri a_Procedures_2009.pdf.

[11] Accreditation Board for Engineering and Technology (ABET), Accreditation Policy and Procedure Manual, ABET Inc., Baltimore, MD, 2010. Available from http://www.abet.org/Linked\%20DocumentsUPDATE/Program\%20Docs/abet-appm-2011-2012.pdf.

[12] W. Isaacs, Dialogue and the Art of Thinking Together: A Pioneering Approach to Communicating in Business and Life, Doubleday, New York, 1999.

[13] J. Ashworth, "Prepare, Plant, Cultivate, Harvest: A Field Guide to Convening Dialogue”, Simon Fraser University, Vancouver, 2010.

[14] P. Senge, P. Scharmer, J. Jawaorski, and B.C.. Flowers, Presence: Exploring Profound Change in People, Organizations, and Society, Currency, New York, 2005.

[15] D. Yankelovich, The Magic of Dialogue: Transforming Conflict into Cooperation, Simon and Schuster, New York, 1999.

[16] N. Kline, Time to Think: Listening to Ignite the Human Mind, Ward Lock Cassell Illustrated, London, 1999, 2002.

[17] Anita Borg Institute, http://anitaborg.org/

[18] Canadian Engineering Leadership Forum, Leading a Canadian Future: The New Engineer in Society, Montreal Declaration, National Engineering Summit, Montreal, QC, 2009 .Available at: http://www.engineerscanada.ca/ files/pam_e_Summit_Declaration_English_Final.pdf.

[19] D. Grasso, M.B. Burkins, J. Helble, and D. Martinelli, "Dispelling the Myths of Holistic Engineering", in Holistic Engineering Education: Beyond Technology. D. Grasso \& M. B. Burkins (Eds.). Springer, New York, 2010, pp. 159165. 